\title{
Correction to: The mineralization of oxalic acid and bio-treated coking wastewater by catalytic ozonation using nickel oxide
}

\author{
Kaiyi $\mathrm{Wu}^{1} \cdot$ Fengzhen $\mathrm{Zhang}^{1} \cdot$ Haizhen $\mathrm{Wu}^{2} \cdot$ Chaohai Wei ${ }^{1,3}$
}

Published online: 29 December 2017

(C) Springer-Verlag GmbH Germany, part of Springer Nature 2017

\section{Correction to: Environ Sci Pollut Res}

$$
\text { https://doi.org/10.1007/s11356-017-0597-7 }
$$

In Table 1, " $\mathrm{SO}^{2-4}$ " and " $\mathrm{NO}^{-3}$ " should be corrected to " $\mathrm{SO}_{4}^{2-}$ " and " $\mathrm{NO}_{3}^{-}$", respectively.

The original article was corrected.

The online version of the original article can be found at http://dx.doi.org/ 10.1007/s11356-017-0597-7

$\triangle$ Chaohai Wei

cechwei@scut.edu.cn

1 School of Environment and Energy, South China University of Technology, 382 Waihuan East Road, Guangzhou Higher Education Mega Center, Guangzhou 510006, China

2 School of Bioscience and Bioengineering, South China University of Technology, Guangzhou 510006, People's Republic of China

3 The Key Lab of Pollution Control and Ecosystem Restoration in Industry Clusters, Ministry of Education, South China University of Technology, Guangzhou 510006, People's Republic of China 